九州大学学術情報リポジトリ

Kyushu University Institutional Repository

\title{
Analytical Expression for Formation of Indigestible Materials and Increase in Dry Matter Indigestibility with Growth of Some Tropical Grasses
}

Shimojo, Masataka

Laboratory of Forage Science and Animal Behaviour, Faculty of Agriculture, Kyushu University

Masuda, Yasuhisa

Laboratory of Forage Science and Animal Behaviour, Faculty of Agriculture, Kyushu University

Bungo, Takashi

Laboratory of Forage Science and Animal Behaviour, Faculty of Agriculture, Kyushu University

Kawamura, Toshihisa

Laboratory of Forage Science and Animal Behaviour, Faculty of Agriculture, Kyushu University 他

https://doi.org/10.5109/24104

出版情報：九州大学大学院農学研究院紀要. 40 (1/2)，pp. 179-188，1995-12. Kyushu University バージョン：

権利関係 : 


\title{
Analytical Expression for Formation of Indigestible Materials and Increase in Dry Matter Indigestibility with Growth of Some Tropical Grasses
}

\author{
Masataka Shimojo, Yasuhisa Masuda, Takashi Bungo, \\ Toshihisa Kawamura and Ichiro Goto
}

\author{
Laboratory of Forage Science and Animal Behaviour, Faculty of Agriculture, \\ Kyushu University, Fukuoka 812-81, Japan \\ (Received July 31, 1995)
}

\footnotetext{
This study was conducted to analyse the formation of indigestible materials and the increase in dry matter indigestibility with growth of some tropical grasses, using proposed formulae.

Formulae for the formation of indigestible materials are,$$
\frac{1}{W} \cdot \frac{d I}{d t}=\left(\frac{1}{W} \cdot \frac{d L}{d t}\right) \cdot \frac{d I}{d L} \quad \text { and } \quad \frac{1}{W} \cdot \frac{d L}{d t}=\frac{C}{W} \cdot\left(\frac{1}{C} \cdot \frac{d L}{d t}\right)
$$

where $W=$ dry weight of forage, $I=$ dry weight of indigestible materials,

$\mathrm{I},=$ amount of lignin, $C^{\prime}=$ amount of cell wall constituents $(\mathrm{CWC})$,

$(1 / W) \cdot(d I / d t)=$ formation rate of $I(\mathrm{FRI}),(1 / W) \cdot(d L / d t)=$ formation rate of $\mathrm{I},(\mathrm{FRL}), d I / d L=$ formation of $I$ per unit increase in $L(\mathrm{FIL}), C / W=\mathrm{CWC}$ ratio, $(1 / C) \cdot(d L / d t)=$ Specific FRL.

Mean value over the interval $t$ to $t_{2}$ for FRI, FRL, FIL, CWC ratio or Specific FRL was calculated and designated as FRI, FRL, $\overline{\text { FIL, }} \overline{\text { CWC ratio }}$ or Specific FRL.

A formula for the increase in dry matter indigestibility (DMI) is as follows,

$$
\frac{I_{3}}{W_{2}}-\frac{I_{1}}{W_{1}}=\left(1-\frac{W_{1}}{W_{2}}\right) \cdot\left(\overline{\overline{\mathrm{FRI}}}-\frac{I_{1}}{W_{1}}\right)
$$

where $\mathrm{RGR}_{\mathrm{u}}=$ mean relative growth rate of forage, $W, \neq W_{2},\left(\mathbf{1}-W_{1} / W_{2}\right)=$ forage growth index (FG index), $\left(\overline{\mathrm{FRL}} / \overline{\mathrm{RGR}}_{4}-I_{1} / W_{1}\right)=$ dry matter partition index into indigestible materials (DMP index).

These formulae accounted for the differences in the formation of indigestible materials and those in the increase in dry matter indigestibility between species or between growth intervals for some tropical grasses.

It was suggested that proposed formulae were available for analyses of the formation of indigestible materials and the increase in dry matter indigestibility with growth of grasses.

\section{INTRODUCTION}

The ruminant production from forages is affected by the amount of digestible dry matter eaten by the animals. The dry matter digestibility of forage generally falls with growth due to the increase in the proportion of indigestible materials.

The indigestible materials are formed from both digestible materials present in forage and new photosynthates (Masuda, 1985). The formation from new photosynthates was shown by a radioisotopic work of Balasko et al. (1981) who measured, with timothy herbage, the rate of incorporating carbon-14 into the indigestible fraction at different stages of growth. Masuda (1985) showed, by applying an analytical method to green panic plants grown under different environmental temperatures, that the larger rate of 
relative growth of indigestible dry matter was related with a larger rate of transformation from the digestible materials. Masuda (1985) also related the increase in dry matter indigestibility with the relative growth rate of indigestible dry matter, that of dry matter and the growth interval.

The analytical approach is considered one of the useful methods to investigate the formation of indigestible materials and increase in dry matter indigestibility. However, more studies are required which include the effects of anti-digestion components in forage. The components depressing forage digestibility are mostly lignin and silica (Van Soest, 1982; Minson, 1990). Lignin is formed in forage as a secondary metabolite and the content increases with growth of forage. Silica is absorbed from soil by plant roots (Jones and Handreck, 1967). There is a difference in the way of depressing forage digestibility between lignin and silica. Lignin incrusts plant fibres and protects them from rumen microbes. Silica depresses forage digestibility by being deposited on plant fibres (Van Soest, 1982), but a portion of silica is dissolved into the rumen fluid and depresses the activity of rumen microbes (Smith and Nelson, 1975; Smith and Urquhart, 1975) and that of cellulase (Shimojo and Goto, 1985, 1989). The content of lignin is generally higher than that of silica unless forages are grown on soil rich in silica or under water logging condition like a paddy field. Therefore, lignin is usually considered a main factor affecting the indigestibility of forage.

This study was designed to investigate an analytical expression for the formation of indigestible materials and increase in dry matter indigestibility with growth of forage under the effects of formation of cell wall and lignin, and followed by their applications to some tropical grasses.

\section{ANALYTICAL EXPRESSION FOR FORMATION OF INDIGESTIBLE MATERIALS AND INCREASE IN DRY MATTER INDIGESTIBILITY}

\section{Formation rate of indigestible materials}

It is known that the rate of relative growth is preferable to that of absolute growth when comparing the growth between plants different in size (Hunt, 1990a,1990b). This was applied to indigestible materials when their relative growth rates were compared between green panic plants grown under different environmental temperatures (Masuda, 1985).

In this paper the formation rate of indigestible materials in forage (FRI) is taken up and its instantaneous value is described in the same way as the production rate of leaf, stem or root in plant (Hunt, 1990c).

Thus.

$$
\mathrm{FRI}=\frac{1}{W} \cdot \frac{d I}{d t}
$$

where $W=$ dry weight of forage, $I=$ dry weight of indigestible materials.

Likewise, the formation rate of lignin in forage (FRL) is expressed as follows,

$$
\mathrm{FRL}=\frac{1}{W} \cdot \frac{d L}{d t}
$$

where $L=$ amount of lignin. 
Combining formulae (1) and (2) gives

$$
\frac{1}{W} \cdot \frac{d I}{d t}=\left(\frac{1}{W} \cdot \frac{d L}{d t}\right) \cdot \frac{d I}{d L}
$$

where $d I / d L=$ formation of $I$ per unit increase in $L(\mathrm{FIL})$.

Formula (3) indicates that FRI is expressed as the product of FRL and FIL, namely, as the relative contribution of FRL and FIL to FRI. Lignin incrusts a portion of fibres constructing the cell wall of forage. This lignin-fibre complex is the major component of indigestible materials, because the cell contents are highly digestible (Van Soest, 1982; Minson, 1990). The description of $L-I$ relationship appears to take no other forms than the form dI/dL (FIL) due to the observation that the increase in $L$ affects the increase in I. Therefore, the first term in the right side of formula (3) is rewritten as follows when the amount of cell wall constituents comes between Wand $L$,

$$
\frac{1}{W} \cdot \frac{d L}{d t}=\frac{C}{W} \cdot\left(\frac{1}{C} \cdot \frac{d L}{d t}\right)
$$

where $\mathrm{C}=$ amount of cell wall constituents $(\mathrm{CWC}), C / W=\mathrm{CWC}$ ratio,

$(1 / C) \cdot(d L / d t)=$ Specific FRL.

Thus, the incorporation of formula (4) into formula (3) leads to

$$
\frac{1}{W} \cdot \frac{d I}{d t}-\frac{C}{W} \cdot\left(\frac{1}{C} \cdot \frac{d L}{d t}\right) \cdot \frac{d I}{d L}
$$

Table 1. Analytical methods for formation of indigestible materials and increase in dry matter indigestibility.

a) Abbreviations of measured items

$W \quad$ Dry weight of forage

I Dry weight of indigestible materials

$L \quad$ Amount of lignin

C Amount of cell wall constituents

b) A method for analysing the formation of indigestible materials

\begin{tabular}{ll}
\hline FRI (Formation rate of I per unit of $W)$ & $(1 / W) \cdot(d I / d t)$ \\
FRL (Formation rate of $L$ per unit of $W)$ & $(1 / W) \cdot(d L / d t)$ \\
FIL (Formation of $I$ per unit increase in $L)$ & $d I / d L$ \\
CWC ratio (Ratio of C to $W$ ) & $C / W$ \\
Specific FRL (Formation rate of $L$ per unit of C) & $(1 / C) \cdot(d L / d t)$ \\
\hline & FRI $=($ FRL $) \cdot(\mathrm{FIL})$ \\
FRL $=(\mathrm{CWC}$ ratio $) \cdot($ Specific FRL) \\
FRI $=(\mathrm{CWC}$ ratio) $\cdot($ Specific FRL) $\cdot(\mathrm{FIL})$
\end{tabular}


where FRI is expressed as the product of CWC ratio, Specific FRL and FIL. Therefore, FRI is evaluated by the relative contribution of CWC ratio, Specific FRL and FIL. The descriptions of FRI, FRL, FIL, CWC ratio and Specific FRL with their relationships are listed in Table la.

The mean value over the interval $t_{1}$ to $t_{2}$ for FRI, FRL, FIL, CWC ratio or Specific FRL is approximately as follows,

$$
\begin{aligned}
& \overline{\mathrm{FRI}}=\frac{I_{2}-I_{1}}{t_{2}-t_{1}} \cdot \frac{\log _{v} W_{2}-\log _{w} W_{1}}{W_{2}-W_{1}} \\
& \overline{\mathrm{FRL}}=\frac{L_{2}-L_{1}}{t_{2}-t_{1}} \quad \begin{array}{c}
\log . W_{3}-\log _{1} W_{1} \\
W_{2}-W_{1}
\end{array} \\
& \overline{\mathrm{FIL}}=\frac{I_{2}-I_{1}}{L_{2}-L_{1}} \\
& \text { CWC ratio }=\begin{array}{cc}
\log W_{2}-\log _{1} W_{\mathrm{i}} . & C_{3}-C_{1} \\
W_{2}-w, & \log C_{2}-\log , c
\end{array} \\
& \overline{\text { Specific FRL }}=\frac{L_{2}-L_{1}}{t_{2}-t_{1}} \cdot \frac{\log C_{2}-\log C_{1}}{C_{2}-C_{1}}
\end{aligned}
$$

where $\mathrm{e}=$ the base of natural logarithm, and it assumes that there is a linear relationship between any two obtained from $W, I, L$ and $\mathrm{C}$.

These formulae imply that $I, \mathrm{C}$ and $L$ are formed from both materials present in forage and new photosynthates, but $W$ is formed from new photosynthates.

\section{The increase in dry matter indigestibility}

The increase in dry matter indigestibility (DMI) is described as follows.

$$
\text { Increase in DMI }=\frac{I_{2}}{W}-\frac{I_{1}}{W_{1}}
$$

The increase in DMI is a macro-change, but FRI is a semimicro-change. The FRI will be related to the increase in DMI by the following procedure.

The right side of formula (11) is rewritten as follows.

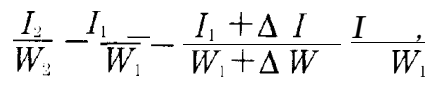

The ratio of FRI to relative growth rate of forage (RGR,,) is taken up as follows.

$$
\begin{aligned}
\frac{\mathrm{FRI}}{\mathrm{RGR}_{*}} & -\frac{\frac{1}{W} \cdot \frac{d I}{d t}}{\frac{1}{W} \cdot \frac{d W}{d t}} \\
= & \frac{d I_{-}}{d W}
\end{aligned}
$$

Therefore,

$$
\mathrm{AI}=\Delta W \cdot \frac{\mathrm{FRI}}{\mathrm{RGR}}
$$

where $\overline{\mathrm{RGR}},=$ mean value of RGR $\mathrm{R}_{\mathrm{u}}$ over the interval $t_{\mathrm{i}}$ to $t_{2}$.

The insertion of formula (14) into formula (12) with arrangement gives

$$
\frac{I_{2}}{W_{2}}-\frac{I_{1}}{W_{1}}=\left(1-\frac{W_{1}}{W_{2}}\right) \cdot\left(\frac{\overline{\mathrm{FRI}}}{\mathrm{RGR}_{\mathrm{W}}}-\frac{I_{1}}{W_{1}}\right)
$$

where $W_{1} \neq W_{2}, \quad\left(\mathbf{1}-W_{1} / W_{2}\right)=$ forage growth index $(\mathrm{FG}$ index $), \quad\left(\overline{\mathrm{FRI}} / \overline{\mathrm{RGR}}-I_{\mathrm{I}} / W_{1}\right)=$ 
dry matter partition index into indigestible materials (DMP index).

The DMP index shows an increase in the partition of dry matter into indigestible materials during the growth of forage. Thus, FRI was taken in DMP index as one of the components. The increase in DMI is expressed as the productof FG index and DMP index (Table lb).

\section{APPLICATIONS OF ANALYTICAL METHODS TO SOME TROPICAL GRASSES}

The forages used in this study are some tropical grasses grown at the experimental field of Faculty of Agriculture, Kyushu University. They are divided into two groups according to the difference in management.

\section{Rhodes grass (Chloris gayana Kunth)}

The characteristics of Rhodes grass cut at 25,41 or 74 days of regrowth are shown in Table 2a. The analytical result of the formation of indigestible materials over the first

Table 2. Characteristics of Rhodes grass, analyses of formation of indigestible materials and increase in dry matter indigestibility.

a) Characteristics of Rhodes grass.

\begin{tabular}{|c|c|c|c|}
\hline Regrowth (days) & 25 & 41 & 74 \\
\hline Dry matter (DM) digestibility"(\%) & 69.68 & 52.24 & 44.97 \\
\hline DM indigestibility"(\%) & 30.32 & 47.76 & 55.03 \\
\hline Cell wall constituents: CWC (\%) & 72.79 & 78.49 & 79.55 \\
\hline $\operatorname{Lignin}^{3}(\%)$ & 3.93 & 7.36 & 8.34 \\
\hline Dry weight (DW) of forage: $W\left(\mathrm{~g} / \mathrm{m}^{3}\right)$ & 223.85 & 398.98 & 593.32 \\
\hline DW of indigestible materials": $I\left(\mathrm{~g} / \mathrm{m}^{\prime}\right)$ & 67.87 & 190.55 & 326.49 \\
\hline Amount of CWC: $C\left(\mathrm{~g} / \mathrm{m}^{\prime}\right)$ & 162.93 & 313.17 & 472.00 \\
\hline Amount of ligninin $: L\left(\mathrm{~g} / \mathrm{m}^{2}\right)$ & 8.81 & 29.36 & 49.45 \\
\hline
\end{tabular}

1) In vitro determination.

2) Acid detergent lignin.

b) Analysis of formation of indigestible materials.

\begin{tabular}{lccc}
\hline Interval & 1st $(\mathrm{P})$ & 2nd (Q) & \\
Length of interval (days) & 16 & 33 & $\mathrm{P} / \mathrm{Q}$ \\
\hline FRI (g/g/day) & 0.0253 & 0.0084 & 3.01 \\
FRL (g/g/day) & 0.0042 & 0.0012 & 3.50 \\
FIL (g/g) & 5.9698 & 6.7666 & 0.88 \\
Sprat rovC (g/g) & 0.7588 & 0.7906 & 0.96 \\
Specific FRL (g/g/day) & 0.0056 & 0.0016 & 3.50 \\
\hline
\end{tabular}

c) Analysis of increase in dry matter indigestibility.

\begin{tabular}{lccc}
\hline Interval & 1st $(\mathrm{R})$ & 2nd $(\mathrm{S})$ & $\mathrm{R} / \mathrm{S}$ \\
\hline Increase in DMI & 0.1744 & 0.0727 & 2.40 \\
FG index & 0.4389 & 0.3275 & 1.34 \\
DMP index & 0.3973 & 0.2219 & 1.79 \\
\hline
\end{tabular}


interval of 16 days or the second interval of 33 days is shown in Table $2 \mathrm{~b}$.

The FRI is 0.0253 over the 1st interval and this value is higher than the value 0.0084 found for the 2 nd interval. This difference is due to a difference in FRL ( 0.0042 versus 0.0012), because FIL shows a smaller difference between the two intervals. The higher FRL during the 1st interval is caused by a higher Specific FRL $(0.0056)$ compared with 0.0016 for the 2nd interval, because there is a little difference in $\overline{\mathrm{CWC}}$ ratio between the two intervals. These results show that a higher formation rate of indigestible materials per unit dry weight of Rhodes grass during the 1st interval may be caused by a higher rate at which cell wall is lignified, when compared with those found for the 2 nd interval.

The analytical result of the increase in dry matter indigestibility is shown in Table $2 \mathrm{c}$. There is a larger increase in DMI for the 1st interval than for the 2nd interval. This is mainly due to a higher DMP index with some contribution of FG index. This result indicates that a larger increase in dry matter indigestibility during the 1st interval may be caused by a larger increase in the partition of dry matter into indigestible materials with some contribution of dry matter increase, when compared with those for the 2 nd interval.

\section{Dallis grass (Paspalum dilatatum Poir.) and bermuda grass (Cynodon dactylon (L.) Pers.)}

The characteristics of dallis grass and bermuda grass grown under the same condition and cut at 20,59 or 80 days of regrowth are shown in Table 3. The analytical result of the formation of indigestible materials over the 1st interval of 39 days or the 2nd interval of 21 days is shown in Table 4a.

(1) Dallis grass: The FRI during the 1st interval is higher than that during the 2nd interval, and this difference is due to a difference in both FRL and FIL (Table 4a). The higher FRL over the 1st interval is caused by a higher Specific FRL when compared with the 2 nd interval. These results show that a higher formation rate of indigestible materials per unit dry weight of dallis grass during the 1st interval may be caused by a higher rate at which cell wall is lignified and a higher efficiency with which lignin produces indigestible materials, when compared with those for the 2nd interval.

The analytical result of the increase in dry matter indigestibility is shown in Table $4 \mathrm{~b}$. There is a slightly smaller increase in DMI for the 1st interval than for the 2nd interval.

Table 3. Characteristics of dallis grass and bermuda grass.

\begin{tabular}{lrrrrrr}
\hline Forages & \multicolumn{3}{c}{ Dallis grass } & \multicolumn{3}{c}{ Bermuda grass } \\
Regrowth (days) & \multicolumn{1}{c}{20} & \multicolumn{1}{c}{59} & \multicolumn{1}{c}{80} & \multicolumn{1}{c}{20} & \multicolumn{1}{c}{59} & \multicolumn{1}{c}{80} \\
DM digestibility"(\%) & 72.25 & 59.78 & 45.81 & 62.42 & 50.13 & 49.18 \\
DM indigestibility'(\%) & 27.75 & 40.22 & 54.19 & 37.58 & 49.87 & 50.82 \\
cwc (\%) & 64.93 & 71.41 & 73.17 & 65.83 & 67.40 & 64.92 \\
Lignin'(\%) & 2.91 & 4.19 & 5.94 & 2.68 & 4.51 & 5.17 \\
$W\left(\mathrm{~g} / \mathrm{m}^{2}\right)$ & 213.20 & 676.53 & 780.40 & 203.40 & 424.80 & 767.20 \\
$\mathrm{I}\left(\mathrm{g} / \mathrm{m}^{\prime}\right)$ & 59.16 & 272.10 & 422.90 & 76.44 & 211.85 & 389.89 \\
$C\left(\mathrm{~g} / \mathrm{m}^{\prime}\right)$ & 338.43 & 483.11 & 571.02 & 133.90 & 286.32 & 498.07 \\
$L\left(\mathrm{~g} / \mathrm{m}^{2}\right)$ & 6.20 & 28.35 & 46.36 & 5.45 & 19.16 & 39.66 \\
\hline
\end{tabular}

1) $I n$ vitro determination.

2) Acid detergent lignin. 
Table 4. Analyses of formation of indigestible materials and increase in dry matter indigestibility in dallis grass and bermuda grass.

a) Analysis of formation of indigestible materials.

\begin{tabular}{lcccccc} 
Forages & \multicolumn{2}{c}{ Dallis grass } & \multicolumn{4}{c}{ Bermuda grass } \\
Interval & 1 st $(\mathrm{P})$ & 2nd $(\mathrm{Q})$ & $\mathrm{P} / \mathrm{Q}$ & 1st $(\mathrm{R})$ & 2nd $(\mathrm{S})$ & $\mathrm{R} / \mathrm{S}$ \\
Length of interval (days) & 39 & 21 & & 39 & 21 & \\
FRI (g/g/day) & 0.0136 & 0.0099 & 1.37 & 0.0115 & 0.0146 & 0.79 \\
FRL (g/g/day) & 0.0014 & 0.0012 & 1.17 & 0.0012 & 0.0017 & 0.71 \\
FL (g/g) & 9.6135 & 8.3731 & 1.15 & 9.8767 & 8.6849 & 1.14 \\
& 6.6873 & 0.7231 & 0.95 & 0.6671 & 0.6603 & 1.01 \\
\hline Specific FRL (g/g/day) & 0.0021 & 0.0016 & 1.31 & 0.0018 & 0.0026 & 0.69
\end{tabular}

b) Analysis of increase in dry matter indigestibility in dallis grass.

\begin{tabular}{lccc}
\hline Interval & $1 \mathrm{st}(\mathrm{P})$ & 2nd $(\mathrm{Q})$ & $\mathrm{P} / \mathrm{Q}$ \\
\hline Increase in DMI & 0.1247 & 0.1397 & 0.89 \\
FG index & 0.6849 & 0.1331 & 5.15 \\
DMP index & 0.1821 & 1.0496 & 0.17 \\
\hline
\end{tabular}

c) Analysis of increase in dry matter indigestibility in bermuda grass.

\begin{tabular}{lccr}
\hline Interval & 1st (R) & 2nd (S) & R/S \\
\hline Increase in DMI & 0.1229 & 0.0095 & 12.94 \\
FG index & 0.5212 & 0.4463 & 1.17 \\
DMP index & 0.2358 & 0.0213 & 11.07 \\
\hline
\end{tabular}

This is caused by a lower DMP index which is not made up for by a higher FG index. This result indicates that a slightly smaller increase in dry matter indigestibility during the 1 st interval may be caused by a smaller increase in the partition of dry matter into indigestible materials, when compared with those for the 2 nd interval.

(2) Bermuda grass: The FRI over the 1st interval is lower than that over the 2nd interval, and this difference is due to a difference in FRL (Table 4a). The lower FRL for the 1 st interval is caused by a lower Specific FRL when compared with those for the 2nd interval. These results show that a lower formation rate of indigestible materials per unit dry weight of bermuda grass over the 1st interval may be caused by a lower rate at which cell wall is lignified, when compared with those for the 2nd interval.

However, there is a larger increase in DMI for the 1st interval than for the 2nd interval (Table 4c). This is mainly caused by a higher DMP index. This result indicates that a larger increase in dry matter indigestibility during the 1st interval may be caused by a larger increase in the partition of dry matter into indigestible materials, when compared with those for the 2nd interval.

There is another comparison which is made between dallis grass and bermuda grass in the respective intervals (Table 5).

(3) First interval: The FRI for dallis grass is slightly higher than that for bermuda grass, and this difference is due to a difference in FRL (Table 5a). The higher FRL in 
Table 5. Comparison between dallis grass ( $\mathrm{Dg}$ ) and bermuda grass ( $\mathrm{Bg}$ ) for formation of indigestible materials and increase in dry matter indigestibility in the respective intervals.

\begin{tabular}{|c|c|c|c|c|c|c|}
\hline \multirow{2}{*}{$\begin{array}{l}\text { Interval (days) } \\
\text { Forages }\end{array}$} & \multicolumn{3}{|c|}{ 1st (39) } & \multicolumn{3}{|c|}{ 2nd (21) } \\
\hline & $\operatorname{Dg}(\mathrm{P})$ & $\mathrm{Bg}(\mathrm{R})$ & $\mathrm{P} / \mathrm{R}$ & $\operatorname{Dg}(Q)$ & $\mathrm{Bg}(\mathrm{S})$ & $\mathrm{Q} / \mathrm{S}$ \\
\hline FRI (g/g/day) & 0.0136 & 0.0115 & 1.18 & 0.0099 & 0.0146 & 0.68 \\
\hline FRL (g/g/day) & 0.0014 & 0.0012 & 1.17 & 0.0012 & 0.0017 & 0.71 \\
\hline FIL $(g / g)$ & 9.6135 & 9.8767 & 0.97 & 8.3731 & 8.6849 & 0.96 \\
\hline$\overline{\text { CWC ratio }}(\mathrm{g} / \mathrm{g})$ & 0.6873 & 0.6671 & 1.03 & 0.7231 & 0.6603 & 1.10 \\
\hline$\overline{\text { Specific FRL }}$ (g/g/day) & 0.0021 & 0.0018 & 1.17 & 0.0016 & 0.0026 & 0.62 \\
\hline
\end{tabular}

b) Analysis of increase in dry matter indigestibility in the 1st interval.

\begin{tabular}{llll} 
Forages & $\mathrm{Dg}(\mathrm{P})$ & $\mathrm{Bg}(\mathrm{R})$ & $\mathrm{P} / \mathrm{R}$ \\
Increase in DMI & 0.1247 & 0.1229 & 1.01 \\
FG index & 0.6849 & 0.5212 & 1.31 \\
DMP index & 0.1821 & 0.2358 & 0.77 \\
\hline
\end{tabular}

c) Analysis of increase in dry matter indigestibility in the 2nd interval.

\begin{tabular}{lccc}
\hline Forages & Dg (Q) & $\mathrm{Bg}(\mathrm{S})$ & $\mathrm{Q} / \mathrm{S}$ \\
\hline Increase in DMI & 0.1397 & 0.0095 & 14.71 \\
FG index & 0.1331 & 0.4463 & 0.30 \\
DMP index & 1.0496 & 0.0213 & 49.28 \\
\hline
\end{tabular}

dallis grass is due to a higher Specific FRL when compared with bermuda grass. These results show that a higher formation rate of indigestible materials per unit dry weight of dallis grass may be caused by a higher rate at which cell wall is lignified, when compared with bermuda grass.

However, there is almost the same increase in DMI between the two grasses (Table $5 b$ ). This is due to the result that higher FG index (or higher DMP index) offsets lower DMP index (or lower FG index). This result indicates that almost the same increase in dry matter indigestibility for both grasses may be caused by an offset effects between dry matter increase and increase in partition of dry matter into indigestible materials.

(4) Second interval: The FRI for dallis grass is lower than that for bermuda grass, and this difference is mainly due to a difference in FRL (Table 5a). The lower FRL in dallis grass is caused by a lower Specific FRL when compared with bermuda grass. These results show that a lower formation rate of indigestible materials per unit dry weight of dallis grass may be mainly caused by a lower rate at which cell wall is lignified, when compared with bermuda grass.

However, there is a larger increase in DMI in dallis grass than in bermuda grass (Table 5c). This is due to a higher DMP index which more than makes up for a lower FG index. This result indicates that a larger increase in dry matter indigestibility in dallis grass may be caused by a larger increase in the partition of dry matter into indigestible 
materials, when compared with bermuda grass.

There is a study (Masuda, 1985) in which relative growth rate of $I$ (RGR,) is used instead of FRI. The RGR, is as follows when expressed in the similar way as FRI,

$$
\begin{aligned}
\mathrm{RGR}_{\mathrm{t}} & =\frac{1}{I^{r}} \cdot \frac{d I}{d t} \\
& =\frac{C}{I} \cdot\left(\frac{1}{C} \cdot \frac{d L}{d t}\right) \cdot \frac{d I}{d L}
\end{aligned}
$$

where $C / I=$ the ratio of $\mathbf{C}$ to $I$.

Masuda (1985) showed the following formula in which the increase in DMI was related with DMI at time $t_{1}\left(I_{1} / W_{1}\right), \overline{\mathrm{RGR}_{i}}, \overline{\mathrm{RGR}_{w}}$ and time interval.

$$
\frac{I_{I_{2}}}{W_{2}} \quad \bar{W}_{1} \quad I_{1} \cdot\left[\exp \left\{\left(\overline{\mathrm{RGR}_{1}}-\overline{\mathrm{RGR}_{W}}\right) \cdot\left(t_{2}-t_{i}\right)\right\}-1\right]
$$

where $\overline{\mathrm{RGR}_{\mathrm{i}}}=$ mean value of RGR, over the interval $t_{1}$ to $t_{2}$

The use of RGR, gives an easier method available even when $W_{1}=W_{2}$. It appears that using FRI is natural in respect of expressing some processes related to the occurrence of indigestion in forage. Multiplying FRI by W/I gives RGR,

In the present study, analytical methods were proposed to investigate the formation of indigestible materials and the increase in dry matter indigestibility. By applying these methods to some tropical grasses different in species or growth intervals; the differences in the formation rate of indigestible materials were explained mainly by the rate at which cell wall is lignified. The differences in the increase in dry matter indigestibility were explained using forage growth index and dry matter partition index into indigestible materials which includes formation rate of indigestible materials as one of the components.

It is suggested from this study that proposed formulae are available for analyses of the increase in indigestible materials and the increase in dry matter indigestibility with growth of grasses.

\section{REFERENCES}

Balasko, J.A., D.P. Knievel and D. Smith 1981 Incorporation of carbon-14 into the indigestible fraction of timothy herbage. Crop Sci., 21: 766-769

Hunt, R. 1990a Absolute growth rates. In "Basic Growth Analysis", Unwin Hyman Ltd., London, pp. 17-24

Hunt, R. 1990b Relative growth rates. In "Basic Growth Analysis", Unwin Hyman Ltd., London, pp. 25-34

Hunt, R. 1990c Compounded growth rates. In "Basic Growth Analysis", Unwin Hyman Ltd., London, pp. $55-72$

Jones, L.H.P. and K.A. Handreck 1967 Silica in soils, plants, and animals. Advan.Agron., 19: 107-148

Masuda, Y. 1985 Analysis of dry matter digestibility of green panic as affected by the change in temperature. Proc. XV Int.Grassl. Congr., 1009-1011

Minson, D.J. 1990 Digestible energy of forage. In "Forage in Ruminant Nutrition", Academic Press, Inc., San Diego, pp. 85-149

Shimojo, M. and I. Goto 1985 Effect of soluble silica on digestion of forage with rumen fluid of goat and cellulase. Jpn.J.Zootech.Sci., 56: 20-24 (in Japanese with English summary)

Shimojo, M. and I. Goto 1989 Effect of sodium silicate on forage digestion with rumen fluid of goats or cellulase using culture solutions adjusted for $\mathrm{pH}$. Anim. Feed Sci. Technol., 24: 173-177 
Smith, G.S. and A.B. Nelson 1975 Effects of sodium silicate added to rumen cultures on forage digestion, with interactions of glucose, urea and minerals. J.Anim.Sci., 41: 891-899

Smith, G. S. and N.S. Urquhart 1975 Effect of sodium silicate added to rumen cultures on digestion of siliceous forages. J.Anim. Sci., 41: 882-890

Van Soest, P.J. 1982 Nutritional quality. In "Nutritional Ecology of the Ruminant", Cornell University Press, New York, pp. 23-74 